\title{
EXPLORING THE USE OF TOUCHSCREEN DEVICES FOR CHILDREN WITH SPECIAL EDUCATIONAL NEEDS AND DISABILITIES: DIGITAL VS TRADITIONAL
}

\author{
Fatma Canan Durgungoz ${ }^{1 \mathrm{i}}$, \\ Ahmet Durgungoz ${ }^{2}$ \\ ${ }^{1} \mathrm{PhD}$, Child Development, \\ Faculty of Health Sciences, \\ Ahi Evran University, \\ Kirsehir, Turkey \\ ${ }^{2}$ Computer Education and Instructional Technology, \\ Mersin University, \\ Mersin, Turkey
}

\begin{abstract}
:
This research explores the use of touchscreen devices with children with special educational needs and disabilities (SEND) regarding their engagement with schoolwork. The participant children's attention, interaction and success with tablet computers and traditional materials were evaluated to fulfil the research aims. The study was conducted in a special needs education institution in Turkey. Video recording and observation were used to collect data. Seven students with different special needs participated in this study. Four sessions were held with each child; two sessions were held with traditional materials, and the other two sessions were held with the touchscreen device. Paired Sample T-Test was used to assess children's attention and interaction time within two different conditions. Wilcoxon Test was used to analyse the success of children. The results show that the participants' attention time was longer with the touchscreen device. Children's interaction time and their success with the device were related to the mobile application. Observation data indicated that not all aspects of the applications were suitable for the students, which negatively affected their learning experience. This study concludes that although an increase of interest in introducing a new tool might have a primary role in the participants' engagement, digital mobile devices could become indispensable for children with SEND. Therefore, more efforts should be canalised into developing mobile software that is carefully tailored for specific disabilities and individual needs.
\end{abstract}

Keywords: touchscreen device, children with SEND, mobile devices in education, digital learning in special needs education

i Correspondence: email c.durgungoz@ahievran.edu.tr 


\section{Introduction}

Computer-assisted teaching and learning have been used for several decades to improve academic achievement. For the last decade, mobile technologies have been one of the central topics of education research as the opportunities digital mobile technologies have increased, such as with anytime anywhere access to resources (Mize, Bryant, \& Bryant, 2019). The use of touchscreen devices also changed how assistive-technology is perceived in educational settings as digital technology has become more of a day-to-day tool than mounted into a part of the school and only accessed within the four walls of institutions (Moreno, 2020).

Another advantage of using touchscreen devices is that they can use multi-media resources. This makes these tools even more paramount, considering children with special needs (e.g. mental disabilities) might tend to learn late and forget in a short time (Soykan \& Özdaml1, 2017). Therefore, using technology-enhanced, multi-media resources could make their learning experience more robust and permanent (Soykan \& Özdaml1, 2017).

\section{Use of tablet PCs in education for children with SEND}

The most useful features of tablet-assisted learning are the fun and easy-to-use aspects that students found to be superior to the day-to-day materials they use (Moreno, 2020). Moreno (2020) reported that the students acknowledged the personalised learning pace. Although one of the students showed a lower improvement than his peers, he still preferred using a tablet-device (Moreno, 2020). A meta-analysis of studies that explored the use of touchscreen devices concluded that using tablets as a supplementary tool has a significant effect on students' math and reading skills (Aspiranti, Larwin, \& Schade, 2020).

SEND teachers also expressed their positivity about using touchscreen devices in a special needs institution, notably to support students with ASD (Autism Spectrum Disorder), weak fine motor skills, and attention deficit (Johnson, 2013). They stated that improving these students' language skills using touchscreen devices is favoured, although supporting math skills were also mentioned. The studies that involved elementary-age students with various disabilities (ASD, attention deficit hyperactivity disorder, down syndrome) have also reported positive outcomes with regards to reading skills (Fernández-López, RodríGuez-Fórtiz, Rodríguez-Almendros, \& Martínez-Segura, 2013), pre-calculus (Engel \& Green, 2011) and math skills of students with emotional, behavioural disorders (Haydon et al., 2012).

A mixture of hands-on and iPad-assisted approaches was found effective for improving oral reading fluency of $5^{\text {th }}$-grade students with special needs. Such an approach revealed a positive impact on oral reading fluency (Mize et al., 2019). For example, tablet PCs' impact was investigated on children with reading difficulties by Gasparini and Culén (2012). They found that tablet PCs can decrease reading problems 
such as stigmatisation. The impact of technology on children with ASD assessed by Hourcade, Bullock-Rest and Hansen, 2012 and they concluded that mobile applications could improve prosocial behaviours of children with ASD. Sigafoos (2011) also evaluated the effect of various technological devices (iPod, Tablets, Computers) on children with a severe level of disabilities and stated that these devices could help children improve their communication and academic skills, besides increasing the enjoyment of lessons.

\section{Mobile applications for children with SEND}

More opportunities have surfaced with the improvements of mobile technologies (Hwang, Chu, \& Lai, 2017), and new strategies have been sought to meet students' needs with learning difficulties (Stephenson \& Limbrick, 2015). Rodríguez and Cumming (2017) highlighted how an application used in tablet computers improved students' language skills. This leaded the device aspect, and the suitability and accessibility of the software content remain vital for a quality learning experience.

The use of mobile technologies enabled learners to access resources anytime, anywhere and carry out learning activities on the Internet (Rodríguez \& Cumming, 2017). However, the software and the learning platforms have not seen this transformation since most of them are not suitable in terms of responsiveness and accessibility for mobile devices (Hu \& Han, 2019; Nordström, Nilsson, Gustafson, \& Svensson, 2019). Although the number of research has increased over the years, the ways that tablet applications are used remained conservative (Cheng \& Lai, 2020). The behaviourist approach seemed to be the making way of delivering the learning content, and also the applications are mostly used to access resources rather than offer a productive, interactive environment. Hwang et al. (2017) also pointed out that multiple aspects should be considered without overfocusing on technology when students with special needs use assistive technology. These include learning theories, learning platforms, children's specific needs, and new trends in technology-enhanced learning.

Beyond basic mobile applications, there have also been studies that utilised various teaching methods for special needs students. For example, Lin et al. (2016) used augmented reality to create a crossword game for special needs students. They reported that the students could complete the tasks independently in a short period and had higher motivation than traditional teaching strategies. Cullen (2014) also introduced a new tablet PC which is called "augmentative and alternative communication (ACC) DynaVoxT10" in a Spectronics Conference ${ }^{i i}$, which is designed for people with complex communication needs. ACC supports children's communication, language, and literacy skills by expressing themselves using symbols, photos, words, and letters. In another study, Allen, Hartley, and Cain (2015) compared the use of traditional books and iPads with students who have autism. It was reported that the students showed better performance with iPads; however, it was highlighted that the content of learning material was the main factor that affected this outcome rather than the medium it was used.

ii https://www.spectronics.com.au/blog/new-technologies/the-dynavox-t10-a-new-tablet-device-for-aac/ 


\section{Mobile Education Technologies in Turkey}

Studies about the use of mobile devices for children with SEND dates to 2000 in Turkey (Silman, Yaratan, \& Karanfiller, 2017). For instance, a study conducted with parents of children with SEND showed that parents have positive attitudes towards using new tools and mobile applications (Kuzu, Cavkaytar, Odabaşı, Erişti, \& Çankaya, 2014). The authors stated that teaching daily life skills via mobile applications was found straightforward (ibid). Another application developed for the use of children with SEND's education revealed that children's interest and attitude towards the session increased (Soykan \& Özdamlı, 2017; Soykan, Özdamlı, \& Özcan, 2017). Eliçin and Tunalı (2016) also confirmed that children with ASD were motivated when a touchscreen device was used in their education setting.

However, there are also shortcomings reported around suitable mobile applications for children with SEND. It was underlined that "the software developed as a special education aid is not sufficient for the teaching of different knowledge and skills" (Silman et al., 2017, p.369), which means that applications were not adaptive to individual children's learning differences. For this reason, researchers developed software that can be adapted to different levels and learning speeds of an individual child with SEND (Silman et al., 2017). This software aimed to teach the basic concepts of quantity, width, length, and size. The study confirmed the importance of considering individual differences and the need for developing more mobile applications suitable for children with SEND. Furthermore, a more recent study also confirmed that the use of digital devices in SEND education is quite limited due to the lack of suitability and facility of the devices (Cagiltay, Cakir, Karasu, Islim, \& Cicek, 2019).

Considering the advantages and shortcomings of mobile technologies in SEND education, this study aims to explore the impact of touchscreen devices on the engagement of children with SEND. The research question proposed below will explore how touchscreen devices distinguish from traditional materials in terms of interaction, attention, success, and preference of children with SEND. Whether or how using a touch screen device influences children's engagement with SEND compared to traditional materials?

\section{Method}

A mixed-methods approach was employed to investigate the participants' preference and performance during the lessons where researchers used traditional materials and a touchscreen device. Both quantitative and qualitative methods were used to analyse the data. The video recording methods and observations were employed to comprehend and explore this study's aim. Two Turkish-English speaking researchers conducted data analysis to increase the study's reliability. 


\subsection{Participants}

This study was implemented in the province of Hatay, Turkey. Cohen, Manion, and Morrison (2000) emphasised the importance of a small sample size for qualitative research. They underlined that "sample size might also be constrained by cost in terms of time, money, stress, administrative support, the number of researchers, and resources" (p.93). Seven children (7-8 years old) with SEND in a private institution were allocated to the research. These children have different sorts of disability (C1: ASD, C2: Mild Mental Retardation, C3: Down's syndrome, C4: ADHD, C5: Moderate Mental Retardation, C6: Down's Syndrome, C7: Moderate Mental Retardation). Since this study investigates the impact of touchscreen devices on SEND children's engagement, the participants were not chosen randomly. The researchers chose each child to have a better and precise outcome. This method is called "purposive sampling",, which is a common method in qualitative research (Flick, 2018) to understand the attitudes and reactions of children with SEND towards mobile technologies.

\subsection{Materials}

Four video recording sessions were conducted with each child to understand whether there is any difference in children with SEND's engagement with schoolwork. Two sessions were carried out with traditional methods. The other two sessions were conducted with touch screen applications to see the differences between children's attention, interaction, success, and preference. Each session lasted around thirty minutes. In the traditional session, materials available in the institution such as toys, puzzles, storybooks, and notebook were used. The researcher and the SEND teachers selected several mobile applications for the sessions in which a tablet device was used.

\subsection{Procedure and Scoring}

To assess children's attention and interaction time, each child was taken separately into four different sessions, each of which lasted thirty minutes: two with traditional methods and materials, the other two with touchscreen devices. During the first five minutes of each session, the researcher played games with each child to warm-up and prepare them for the session. All sessions were recorded by two cameras which were in different positions. One camera directly recorded the children's face and movements; the other recorded both the researcher and the child from one corner of the session room. The second camera was helpful because if the child stood up from his or her seat and moved, it helped researchers see what the child did and what happened. These video recordings were analysed by using continuous coding.

Each child with SEND was observed for several duration event channels: visualfocus, head-motions and hand-motions for their attention time (Zhang, Wu, Fournier Viger, Van, \& Tseng, 2017) and touches to screen for their interaction time. Their attention and interaction acts were calculated with a timekeeper. When the children started (onset) to look at the material and stopped looking at it, the researcher recorded the time with a timekeeper. If the participants started looking at the material again, the timekeeper was 
started again and stopped when they finished looking at the material. This process continued until the thirty minutes' session finished.

Additionally, each child's touching time was calculated in the same way. Their looking (attention) and touching (interaction) durations in the sessions were visualised in a graph with their percentages. Also, Pair t-test was used for both interaction and attention time to compare the sessions with the touchscreen device and traditional material to see if there is a significant difference between the two dependent samples.

To understand the impact of touchscreen devices on children's emotions, researchers separately and periodically rated every child's feelings during the session within every thirty seconds. Similarly, classifying and rating the learners' feeling, an educated observer method is used in some other studies (Calvo \& D'Mello, 2011). The review of emotions by Ekman and Cordaro (2011) was also utilised to rate the children's basic emotions described in the literature as sadness, happiness, anger, fear, disgust, and surprise.

Six questions were asked to each child to assess the participants' learning outcome. These questions were about the session's topic and material that the SEND teacher selected. Their responses to each question were scored as either correct or wrong. The percentages of correct answers were calculated and visualised following each child's correct answers, and they were evaluated with the Wilcoxon test.

The inter-observer agreement method was conducted to assess the reliability of the data. First, two different observers evaluated the reliability of the attention time data, children's visual-focus, hand, and head motions in the sessions. The percentage of the agreement was 91\% (Agreement: 34, Disagreement: 3), and Kappa was found as 0.835, which shows that the agreement is strong. Additionally, children's interaction time in the sessions was also assessed and found that the agreement was \%0.86 (Agreement: 32, Disagreement: 5); and Kappa was 0.668 showing that the agreement is substantial.

\subsection{Observation Data}

Another data generation method used in this study is observation. Observation in scientific research is defined as "the systematic description of events, behaviours, and artefacts in the social setting chosen for study" (Marshall \& Rossman, 2014, p.79). Researchers use "active looking, improving memory, informal interviewing, writing detailed field notes"(Musante \& DeWalt, 2010, p.7). Method of observation is also defined as "the process of learning through exposure to or involvement in the day-to-day or routine activities of participants in the researcher setting" (Schensul, Schensul, \& LeCompte, 1999, p.91).

In this study, two researchers actively observed the sessions, and one of the researchers took field notes whilst the other researcher directly engaged with the participants. The sessions were also video recorded, which enabled the researchers to rewatch the sessions together to analyse the participants' facial expressions, behaviours, and actions. Video recordings also allowed writing down the participant's natural statements in the sessions, which can be described as informal interviewing. It should be 
noted that the researchers paid extra attention not to lead the children with SEND to give certain statements when comparing touchscreen device and traditional materials.

Two researchers performed the analysis of observation data using Braun and Clarke (2006)'s method of inductive thematic analysis, which takes the data in the centre without having a pre-established framework or theory. First, field notes were read, and video recordings watched together. Each Turkish-English speaking researcher wrote down the participant students' statements and coded these separately. The researchers then coded the participant's facial expressions, actions, and behaviours in each thirty seconds intervals. The researchers then compared and discussed each code by watching the video-recordings and forming the main themes.

\subsection{Ethics}

The British Educational Research Association's (BERA) ethical guidelines were closely followed. Besides, consent to conduct the study was sought and received from the Turkish Ministry of Health and Education and governor of SEN institution. The informed consent of both the SEND teachers and children's parents were also received. The participants' vulnerability was considered, and extra precautions were taken during the session and data collection.

\section{Results}

In this section, data will be presented under four sections. Firstly, the presentation of the proportion of attention time was found by analysing the students' visual-focus, handmotions and head motions. Secondly, the interaction time which was found by calculating the amount of time that each student has made a meaningful interaction with the touchscreen device and traditional material. Thirdly, the success percentage was found by asking questions about the sessions. Fourthly, there will be an analysis of interviews held with children at the end of the sessions.

\subsection{Attention Time}

Figure 1 shows the percentage of attention time for each child when the touchscreen and a traditional tool was used. The figure shows that the percentage of attention time in the sessions held with the touchscreen device is significantly higher than the sessions with traditional material for all the children. While in the sessions with the touchscreen device, all participants' attention time was higher than $76 \%$. An average of all participants' attention time in the sessions with traditional material was $61 \%$. In contrast, C3 shows the highest attention time, with $81.54 \%$ with the traditional method. When it comes to touch screen device, the highest attention time is shown by C1 with 96.72 . The graph also indicates that when the touchscreen device was used, C7's attention had dramatically increased from $42.25 \%$ to $92.32 \%$, whereas there is little difference in the attention time of C3 when the used medium was changed. 


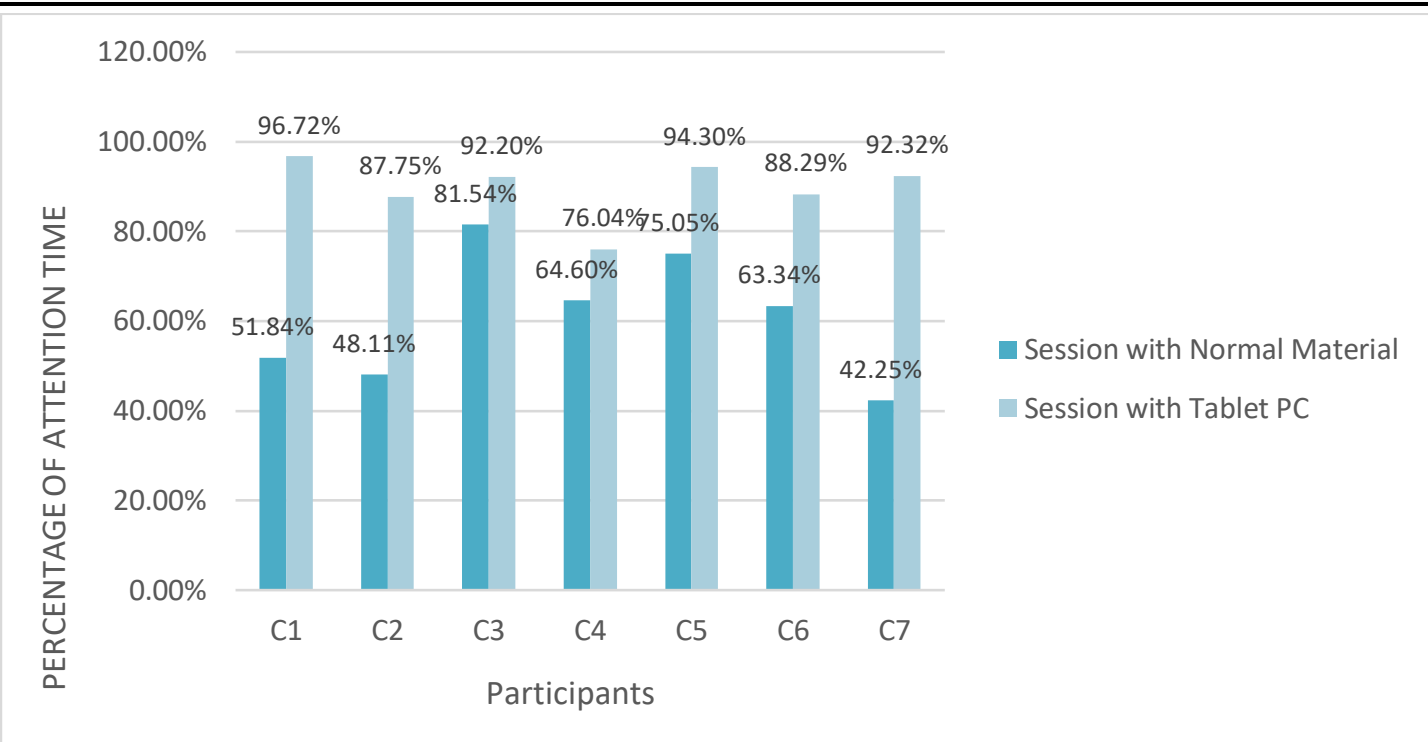

Figure 1: The figure shows the percentage of attention time

A paired-sample t-test was conducted to determine if there are differences between session with the traditional method and session with the touchscreen device's attention time. There was a statistically significant increase in children's attention time from the session with traditional material $(M=60.96, S D=14.37)$ to session with touchscreen device $(M=89.66, S D=6.78), \mathrm{t}(6)=4.7, \mathrm{p}=.003$ (two-tailed). The t-statistic is 4.7016 with 6 degrees of freedom. This means that the difference was statistically significant $(d f=6, t=4.702, p<.05)$. The mean increase in attention time scores was 28.7, with a $95 \%$ confidence interval ranging from -43.63 to -13.76 .

\subsection{Interaction Time}

Figure 2 shows the percentage of interaction time for each child within the two different material conditions. The figure displays that 5 out of 7 children's percentage of interaction time in the sessions with the touchscreen material is higher than the sessions with traditional material. As it can be seen, only C5 and C6 interacted with traditional material more than they did with the touchscreen material, but there is no significant difference between these two materials in terms of their interaction percentage $(\mathrm{C} 5$; touchscreen device: 65,62\%, traditional material: 69,12\%. C6; touchscreen device: $40.34 \%$, traditional material: 43.13). The most significant difference in interaction time is seen in C1 and C7. C1 interacted with the traditional material during $28.62 \%$ of the session and $72.55 \%$ of the session with the touchscreen device.

C1 had the highest interaction time with tablet PC with a percentage of 72.55 , secondly C4 following him with $67.17 \%$ and then C5 with the percentage of $65.62 \%$. When it comes to the session with the traditional materials, the highest percentage is $69.12 \%$ with C5, then C4 with 55.13\%. 


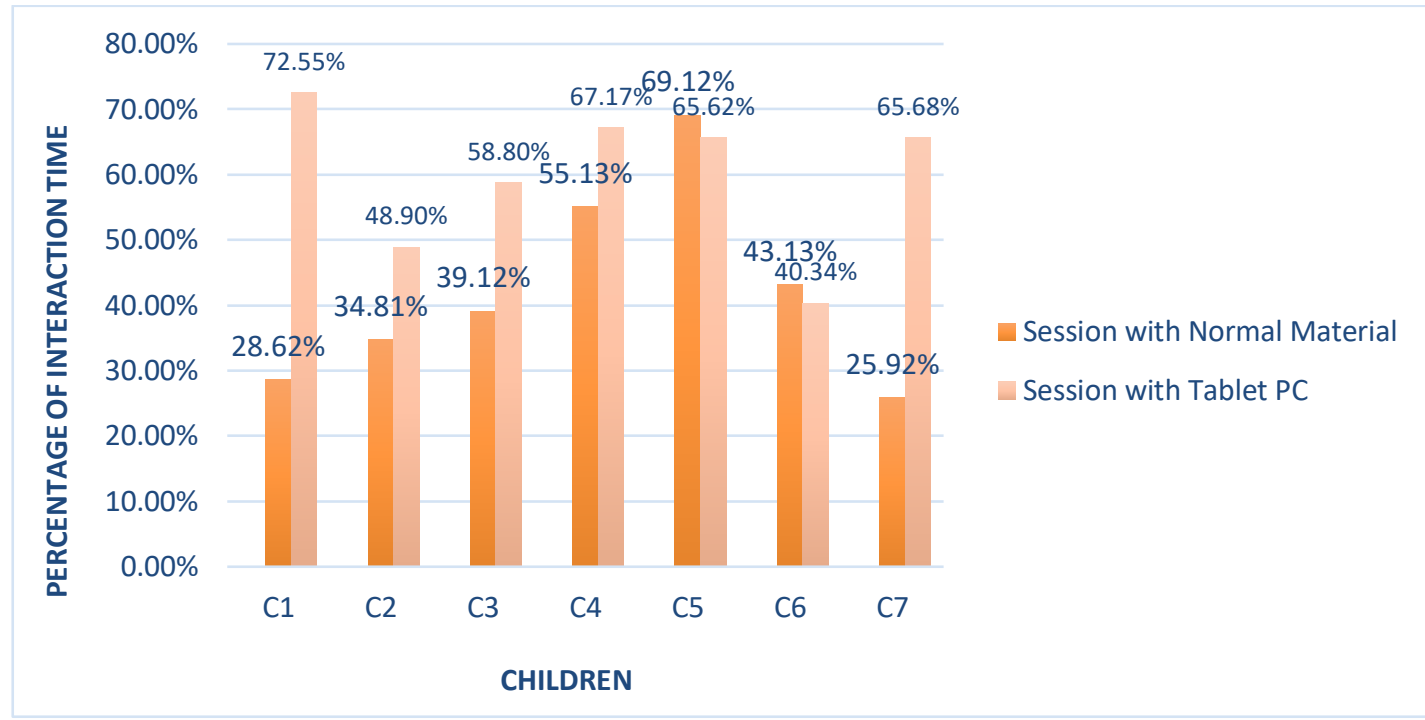

Figure 2: Graph inhibiting the percentage of interaction time

A paired-sample t-test was conducted to evaluate the differences between session with normal material and session with tablet PC's interaction time. There was a statistically significant increase in children's interaction time into the session with normal material $(\mathrm{M}=42.26, \mathrm{SD}=15.31)$ to session with tablet $\mathrm{PC}(\mathrm{M}=60.29, \mathrm{SD}=11.74), \mathrm{t}(6)=2.4724$, $\mathrm{p}=.0483$ (two-tailed). The t-statistic is 2.4724 with 6 degrees of freedom. It means that the difference is statistically significant $(d f=6, t=2.4724, p<.05)$. The mean increase in interaction time scores was 16.18 , with a $95 \%$ confidence interval ranging from -32.75 to .41.

\subsection{Learning Outcomes in Two Different Conditions}

Figure 3 shows each student's success percentages within two different material conditions. Five out of seven children showed better performance in the touchscreen device session. It was found that while C2 showed 50\% of success in the session with traditional material, he gave $100 \%$ correct answers in the session with the touch screen device. Similarly, while C4 gave $33.30 \%$ correct answer in the session with traditional material, he showed $75 \%$ success with a touchscreen device. Also, C3 showed 28.57\% success with traditional material and $60 \%$ success with tablet PC. As can be seen, these participants' learning outcomes almost doubled in the sessions held with the touch screen device. Conversely, C1 and C6 showed more success in the session with traditional material than the touchscreen device session (C6; traditional material: 66.60\%, touchscreen device: $50 \%$, C1; traditional material: 50\%, touchscreen device: $33.30 \%$ ). 


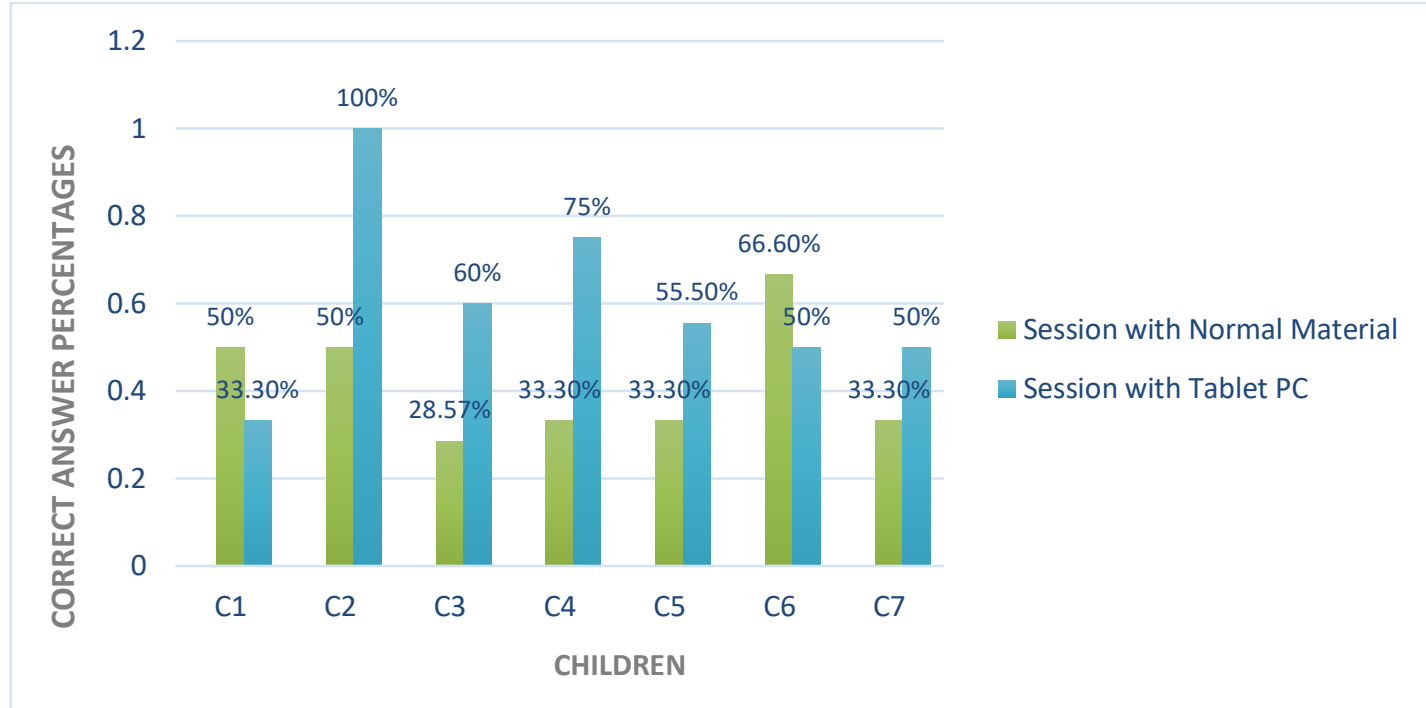

Figure 3: The graph shows the proportion of the success for each child with SEND

The Wilcoxon test was conducted to see differences between the two sessions regarding children's success. The experimental hypothesis predicted a difference between the children's rated success scores in traditional materials session and session with the touchscreen device. The hypothesis was one-tailed because it predicted higher success scores in session with the touchscreen device. (Mean Session with Normal Material: 42, 15; Mean Session with Tablet PC: 60, 54).

Most of the scores in the sessions with the touchscreen device were higher than the sessions with the traditional materials since most of the differences between the sessions were minus. The level of significance for the calculated value of $\mathrm{T}$ indicates that the results of the analysis are significant $(\mathrm{p}<.05$, one-tailed). This means that the success scores are higher in the touchscreen device.

\subsection{Observation Data}

This section will present the results of observations that were held with children. During the sessions, children's behaviour and reaction showed that they favoured the touchscreen device. Regarding the children's behaviour and expressions, it was observed that children were excited and enthusiastic to use the touchscreen device. Observation data will be presented under three themes: preference, enjoyment, and suitability.

\subsubsection{Preference: "Because it is new!"}

In the analysis of the video recordings, both researchers regularly coded the "new" effect of the tablet device. The participants statements such as "never used it here", "the first time I use this", "it is different" were coded under the theme Preference. When one of the children was asked why she wanted to continue with the tablet, she stated, "because it is new..." Although the children stated that they use touchscreen devices such as smartphones and tablets at home, they had never used such devices at the rehabilitation centre. This "novelty" effect might have influenced their preference for the teaching material and their interaction, attention, and success with the tablet device. 
Five out of seven students expressed in the sessions that they prefer to continue with the tablet PC. C1 stated that "Can we keep using the tablet?". Other children's behaviour and reaction showed that they favoured the tablet PC. For example, when the tablet PC was replaced with traditional materials, it was observed that C4 became sad and wanted to use the tablet PC. Also, after the tablet PC was changed for C7 and was asked his preference, it was seen that he could not take his eyes from the device, and he continued to interact with the tablet device. At the same time, he said that, "It does not matter, we can continue with whatever you want; but, we have already switched the tablet PC on". Another similar situation was seen with C6. When the tablet PC was replaced with traditional material, it was observed that C6 was surprised and said: "I liked this (pointing the tablet PC)" (C6).

\subsubsection{Enjoyment}

It was seen that almost all children enjoyed using the touchscreen device during the session. The researchers observed that participants showed their happiness almost every thirty seconds within thirty minutes' sessions by using more positive facial expressions such as smiling and laughing when engaging with the touchscreen device.

It was observed that C7 could not take his eyes from the device, and he continued to interact with the touchscreen device, and at the same time, he showed great enthusiasm to use the touchscreen device. Furthermore, some children clearly expressed their enjoyment in the sessions with the touchscreen device. C6 said that "The lesson was very enjoyable". C7 made a similar statement by saying, "It was fun". Moreover, C1 stated, "I enjoyed this lesson; it includes many games". Reading a story from a touchscreen device is perceived as playing a game by $\mathrm{C} 1$. When practising math skills, the child was trying to touch the balloons, which include a question and its answer. Suppose the child touch the balloon that includes a question and the balloon that includes its correct answer; these two balloons burst. Instead, the child seemed to feel that he have to learn something; he seemed to feel like playing a game. C5 said, "This was much nicer".

\subsubsection{Suitability}

Even though the children favoured the touchscreen device with SEND in this study, two children expressed that they prefer the usual material because they stated that they are not familiar with the device. C2 mentioned his health issues when using the touchscreen device; he said: "hurting my eyes" (C2), which led him to choose traditional materials over touchscreen devices. So, it is possible to say that apart from the disability, additional health problems can have an important impact on preference. This example shows that individual differences and secondary problems can affect children's preference. In the session of C5, it was observed that he was hesitated to use and touch the device and said: "I do not know how to use a computer (means touchscreen device)". He preferred to continue the session with the materials that he used to. 
Another important finding was that during the observation session, it was seen that while children wanted to touch something on the applications, they sometimes touched the exit button accidentally. Moreover, visible items on the screen, such as the connector, also distracted some children's attention. For example, when reading a story C1 (a child with ASD), he continuously touched the interactive objects to move them. Also, he was always looking at the clock on the screen and repetitively saying the time. It was observed that although $\mathrm{C} 1$ was interacting and giving his attention well to the touchscreen device, he showed better success with the traditional material.

\section{Discussion and Conclusion}

This study aimed to explore the impacts of using touchscreen devices in children with SEND's attention, interaction, and success. The results showed that all children with SEND in this study showed better attention, and most children showed better interaction and success in the session with the touchscreen device. However, some children showed better interaction and success with the usual materials. Various factors affected their engagement with the materials, such as familiarity with the material or other health issues.

\subsection{Touchscreen device outperforming traditional materials but creating confusion}

Firstly, attention time results show a statistically significant difference between the sessions with traditional materials and the touchscreen device sessions. All children's attention time (visual-focus, head, and hand motions) with the touchscreen device is higher than the traditional materials. Similarly, Clark and Luckin (2013) posited that touchscreen devices "can motivate and engage students" (p.2) for a longer time on their task. Clarke, Svanaes, and Zimmermann (2013) also claimed that touchscreen device could help students to have better attention and motivation towards their lesson because it has "multi-sensory and multitouch technology" (p.61). Also, they compared tablet PC and desktop; they found that children's attention is better on tablet PCs. Moreover, Soykan and Özdamlı (2017) conducted a sentiment analysis while students with mental disabilities used a touchscreen device and reported increased happiness and satisfaction. This study yielded the importance of the touchscreen device's feature. As shown in the data, the applications that include many stimuli such as colours, pictures, buttons, or texts might not be suitable for many children with special needs due to cognitive load. Since ASD people generally see the details rather than the general picture, these kinds of objects on the screen could be distracting for them (Soykan \& Özdamll, 2019). As many studies suggest, more attention should be given to designing mobile software to meet children with SEND's individual needs (Choi \& Chan, 2015). Hence, simple, minimal, and straightforward applications that might not seem appealing for regular users could be more productive and suitable for special needs students (Fien et al., 2016). Instructor facilitation is therefore vital with such situations, and there is a need to provide immediate feedback; otherwise, applications create 'drill and kill' experiences for 
children. Some apps also require users to interact with the software, making it difficult for children with low reading skills to use the apps (Moreno, 2020).

Choosing a suitable device that matches students' fine motor skills is also an important factor as some smartphones are found to be too small for students with weak fine motor skills (Chelkowski, Yan, \& Asaro-Saddler, 2019). This study also showed that other health aspects should be considered, such as the brightness of the screen or the tablet applications' fonts, so that students can engage with such technologies longer without any issues (hurting eyes etc.). Gybas, Klubal, and Kostolányová (2019) underlined the need to categorise children's needs, learning strategies, mobile device, and software to help teachers better identify their students' needs and the right assistive technology. Such verified guidelines can facilitate integrating touchscreen devices into special needs institutions where step-by-step instructions might be needed more than other schools.

\subsection{Need for suitable applications and pedagogy}

Secondly, five out of seven children are more likely to prefer to interact with the touchscreen device than the traditional materials. This is also confirmed by Gasparani and Culen (2012). They found that children like to interact and study with touchscreen devices because it includes various applications. In their study, a child with dyslexia expressed that she could zoom the letters when reading or use different colours to highlight related text. Also, since applications can automatically vocalise the chosen text, she could use this feature when she was stuck. As a result, the touchscreen device itself is not enough to provide a meaningful and engaging session for children with SENDs, so the chosen software has a paramount role in the students' learning experience.

One of the most important findings of this study is that applications designed for children with SEND were still inadequate and do not meet the individual child's needs. Soykan and Özdamlı (2017) underline the lack of mobile software applications for educational aims. While touchscreen devices have seen a significant increase over the years, the same cannot be claimed for the mobile application market. The available ones are insufficient regarding user-friendliness, accessibility, feedback, and content. Most Turkish language applications allow users to access website or pdf resources rather than provide an interactive mobile learning experience. It was suggested that a framework that could help instructors to help to find quality tablet applications is significant (Ok, Kim, Kang, \& Bryant, 2016). This study also pointed out, most of the applications are not suitable for students with SEND. The study also highlighted that mobile applications could not give immediate feedback that is clear and enough for children to progress from one task to another. It should also be noted that the feedback mechanism that the mobile applications have does not always align with what the students need to know, which proves to the point that peer or instructor assistance is needed during the use of such digital tools. 


\subsection{Was it a Novelty effect?}

The novelty effect has long been discussed in the literature. It has been underlined that children's increased attention and fun perception might be short-lived due to the novelty of the used material (Cumming \& Rodriguez, 2013; Kagohara, Sigafoos, Achmadi, O’Reilly, \& Lancioni, 2012; Ok \& Kim, 2017). Gasparini and Culén (2012) investigated the use of the iPad in an elementary school. The positivity and enthusiasm for using the iPad faded award towards the end of the year. They reported that iPads mixed with the classroom ecology and was marginalised.

Statistical analysis of the video recordings showed that the children' interaction and attention time were higher in the sessions with the touchscreen device. The children also showed better performance when the session was delivered with the tablet device. However, when the qualitative data was analysed, it was revealed that there is a significant novelty effect of using the tablet device in the children's education setting. The participant children expressed the tablet device's "newness" in their education setting when they talked about their preference and enjoyment. The novelty effect might have also had a crucial impact on the participant's attention, interaction and learning outcomes. Hence, this study recommends conducting longitudinal studies to comprehend how children with various disabilities perceive touchscreen devices in their educational settings.

\section{Competing Interests}

The authors declare that they have no competing interests.

\section{About the Authors}

Fatma Canan Durgungoz has completed her PhD in Special Needs at the University of Nottingham and currently works as a lecturer at the Department of Child Development at Ahi Evran University, Turkey. Orchid ID: 0000-0001-8758-1861.

Ahmet Durgungoz has completed his PhD in Learning, Technology and Education at the University of Nottingham, UK. Currently, he is a lecturer at Computer Education and Instructional Technology at Mersin University, Turkey. Orchid ID: 0000-0001-6666-2232.

\section{References}

Allen, M. L., Hartley, C., \& Cain, K. (2015). Do iPads promote symbolic understanding and word learning in children with autism? Frontiers in psychology, 6, 138-138. doi:10.3389/fpsyg.2015.00138

Aspiranti, K. B., Larwin, K. H., \& Schade, B. P. (2020). iPads/tablets and students with autism: A meta-analysis of academic effects. Assistive Technology, 32(1), 23-30. doi:10.1080/10400435.2018.1463575

Braun, V., \& Clarke, V. (2006). Using thematic analysis in psychology. Qualitative research in psychology, 3(2), 77-101. doi:10.1191/1478088706qp063oa 
Cagiltay, K., Cakir, H., Karasu, N., Islim, O. F., \& Cicek, F. (2019). Use of educational technology in special education: Perceptions of teachers. Participatory Educational Research, 6(2), 189-205.

Calvo, R. A., \& D'Mello, S. K. (2011). New perspectives on affect and learning technologies (Vol. 3): Springer Science \& Business Media.

Chelkowski, L., Yan, Z., \& Asaro-Saddler, K. (2019). The use of mobile devices with students with disabilities: a literature review. Preventing School Failure: Alternative Education for Children and Youth, 63(3), 277-295. doi:10.1080/1045988X.2019.1591336

Cheng, S.-C., \& Lai, C.-L. (2020). Facilitating learning for students with special needs: a review of technology-supported special education studies. Journal of Computers in Education, 7(2), 131-153. doi:10.1007/s40692-019-00150-8

Choi, K.-S., \& Chan, T.-Y. (2015). Facilitating mathematics learning for students with upper extremity disabilities using touch-input system. Disability and Rehabilitation: Assistive Technology, 10(2), 170-180.

Clark, W., \& Luckin, R. (2013). What the research says: iPads in the classroom. London Knowledge Lab, Institute of Education, University of London, 1-31.

Clarke, B., Svanaes, S., \& Zimmermann, S. (2013). One-to-one tablets in secondary schools: an evaluation study. Tablets for schools.

Cohen, L., Manion, L., \& Morrison, K. (2000). Research methods in education: Routledge.

Cumming, T. M., \& Rodriguez, C. D. (2013). Integrating the iPad into language arts instruction for students with disabilities: Engagement and perspectives. Journal of Special Education Technology, 28(4), 43-52.

Ekman, P., \& Cordaro, D. (2011). What is meant by calling emotions basic. Emotion review, 3(4), 364-370.

Eliçin, Ö., \& Tunalı, V. (2016). Effectiveness of tablet computer use in achievement of schedule-following skills by children with autism using graduated guidance. Egitim ve Bilim, 41(183).

Engel, G., \& Green, T. (2011). Cell phones in the classroom: Are we dialing up disaster? TechTrends, 55(2), 39-45.

Fernández-López, A., RodríGuez-Fórtiz, M. J., Rodríguez-Almendros, M. L., \& MartínezSegura, M. J. (2013). Mobile learning technology based on iOS devices to support students with special education needs. Computers $\mathcal{E}$ Education, 61, 77-90.

Fien, H., Doabler, C. T., Nelson, N. J., Kosty, D. B., Clarke, B., \& Baker, S. K. (2016). An examination of the promise of the NumberShire Level 1 gaming intervention for improving student mathematics outcomes. Journal of Research on Educational Effectiveness, 9(4), 635-661.

Flick, U. (2018). Designing qualitative research: Sage.

Gasparini, \& Culén. (2012, 24-26 Sept. 2012). Acceptance factors: An iPad in classroom ecology. Paper presented at the 2012 International Conference on E-Learning and E-Technologies in Education (ICEEE). 
Gybas, V., Klubal, L., \& Kostolányová, K. (2019). Individualisation with Tablets in the Czech Republic-Special Primary Schools. International Association for Development of the Information Society.

Haydon, T., Hawkins, R., Denune, H., Kimener, L., McCoy, D., \& Basham, J. (2012). A comparison of iPads and worksheets on math skills of high school students with emotional disturbance. Behavioral Disorders, 37(4), 232-243.

Hourcade, J. P., Bullock-Rest, N. E., \& Hansen, T. E. (2012). Multitouch tablet applications and activities to enhance the social skills of children with autism spectrum disorders. Personal and ubiquitous computing, 16(2), 157-168.

Hu, X., \& Han, Z. R. (2019). Effects of gesture-based match-to-sample instruction via virtual reality technology for Chinese students with autism spectrum disorders. International Journal of Developmental Disabilities, 65(5), 327-336.

Hwang, G.-J., Chu, H.-C., \& Lai, C.-L. (2017). Prepare your own device and determination (PYOD): a successfully promoted mobile learning mode in Taiwan. International Journal of Mobile Learning and Organisation, 11(2), 87-107.

Johnson, G. (2013). Using Tablet Computers with Elementary School Students with Special Needs: The Practices and Perceptions of Special Education Teachers and Teacher Assistants / Utilisation des tablettes électroniques avec des enfants d'école primaire à besoins spéciaux. Canadian Journal of Learning and Technology / La revue canadienne de l'apprentissage et de la technologie, 39(4).

Kagohara, D. M., Sigafoos, J., Achmadi, D., O'Reilly, M., \& Lancioni, G. (2012). Teaching children with autism spectrum disorders to check the spelling of words. Research in Autism Spectrum Disorders, 6(1), 304-310.

Kuzu, A., Cavkaytar, A., Odabaşı, H. F., Erişti, S. D., \& Çankaya, S. (2014). Development of mobile skill teaching software for parents of individuals with intellectual disability. Turkish Online Journal of Qualitative Inquiry, 5(2), 11-26.

Lin, C.-Y., Chai, H.-C., Wang, J.-y., Chen, C.-J., Liu, Y.-H., Chen, C.-W., . . Huang, Y.-M. (2016). Augmented reality in educational activities for children with disabilities. Displays, 42, 51-54.

Marshall, C., \& Rossman, G. B. (2014). Designing qualitative research: Sage publications.

Mize, M., Bryant, D. P., \& Bryant, B. R. (2019). Teaching reading to students with learning disabilities: Effects of combined iPad-assisted and peer-assisted instruction on oral reading fluency performance. Assistive Technology, 1-8. doi:10.1080/10400435.2018.1559896

Moreno, G. (2020). Expanding Definition of Technology in Special Education: Impact of Training on the Adoption of iPad Tablets by Special Educators. International Journal of Disability, Development and Education, 1-17. doi:10.1080/1034912X.2020.1731432

Musante, K., \& DeWalt, B. R. (2010). Participant observation: A guide for fieldworkers: Rowman Altamira.

Nordström, T., Nilsson, S., Gustafson, S., \& Svensson, I. (2019). Assistive technology applications for students with reading difficulties: special education teachers' 
experiences and perceptions. Disability and Rehabilitation: Assistive Technology, 14(8), 798-808. doi:10.1080/17483107.2018.1499142

Ok, M. W., Kim, M. K., Kang, E. Y., \& Bryant, B. R. (2016). How to Find Good Apps:An Evaluation Rubric for Instructional Apps for Teaching Students With Learning Disabilities. Intervention in School and Clinic, 51(4), 244-252. doi:10.1177/1053451215589179

Ok, M. W., \& Kim, W. (2017). Use of iPads and iPods for Academic Performance and Engagement of PreK-12 Students with Disabilities: A Research Synthesis. Exceptionality, 25(1), 54-75. doi:10.1080/09362835.2016.1196446

Rodríguez, C. D., \& Cumming, T. M. (2017). Employing mobile technology to improve language skills of young students with language-based disabilities. Assistive Technology, 29(3), 161-169.

Schensul, S. L., Schensul, J. J., \& LeCompte, M. D. (1999). Essential ethnographic methods: Observations, interviews, and questionnaires (Vol. 2): Rowman Altamira.

Sigafoos, J. (2011). Introduction to the special issue: Evaluating assistive technology in the education of persons with severe disabilities. In: Springer.

Silman, F., Yaratan, H., \& Karanfiller, T. (2017). Use of assistive technology for teachinglearning and administrative processes for the visually impaired people. Eurasia Journal of Mathematics, Science and Technology Education, 13(8), 4805-4813.

Soykan, E., \& Özdaml, F. (2017). Evaluation of the android software for special needs children. Eurasia Journal of Mathematics, Science and Technology Education, 13(6), 2683-2699.

Soykan, E., \& Özdamlı, F. (2019). Development process of instructional mobile application for special needs children. International Journal of Technology Enhanced Learning, 11(3), 259-278.

Soykan, E., Özdamlı, F., \& Özcan, D. (2017). The emotional analysis of children with special needs during tablet usage in education. International Journal of Cognitive Research in Science, Engineering and Education, 5(2), 57.

Stephenson, J., \& Limbrick, L. (2015). A review of the use of touchscreen mobile devices by people with developmental disabilities. Journal of autism and developmental disorders, 45(12), 3777-3791.

Zhang, X., Wu, C.-W., Fournier Viger, P., Van, L.-D., \& Tseng, Y.-C. (2017). Analysing students' attention in class using wearable devices. 
Fatma Canan Durgungoz, Ahmet Durgungoz

EXPLORING THE USE OF TOUCHSCREEN DEVICES FOR CHILDREN

WITH SPECIAL EDUCATIONAL NEEDS AND DISABILITIES: DIGITAL VS TRADITIONAL

Creative Commons licensing terms

Authors will retain the copyright of their published articles agreeing that a Creative Commons Attribution 4.0 International License (CC BY 4.0) terms wil be applied to their work. Under the terms of this license, no permission is required from the author(s) or publisher for members of the community to copy, distribute, transmit or adapt the article content, providing a proper, prominent and unambiguous attribution to the authors in a manner that makes clear that the materials are being reused under permission of a Creative Commons License. Views, opinions and conclusions expressed in this research article are views, opinions and conclusions of the author(s). Open Access Publishing Group and European Journal of Special Education Research shall not be responsible or answerable for any loss, damage or liability caused in relation to/arising out of conflict of interests, copyright violations and inappropriate or inaccurate use of any kind content related or integrated on the research work. All the published works are meeting the Open Access Publishing requirements and can be freely accessed, shared, modified, distributed and used in educational, commercial and non-commercial purposes under a Creative Commons Attribution 4.0 International License (CC BY 4.0). 